The usefulness of the book is greatly increased by the large number of excellent illustrations which are interspersed in the text and by the copious index. It is, indeed, a book which may be commended to every student of mineralogy, from whatever angle the subject be approached.

\section{Getting Acquainted with Minerals}

By G. L. English. Pp. xi +324 . (New York and London: McGraw-Hill Book Co., Inc., 1934.) $15 s$.

THE veteran author of this book has long been known to those interested in the acquisition of minerals. In 1886-1904, he was actively engaged in mineral dealing under the trade name of George L. English and Co.; for the following nine years, until 1913, he was monazite expert to the National Light and Thorium Company; and finally he returned to his old life, first until 1921 as manager of the mineralogy and petrography department and then until 1934 as consulting mineralogist of Ward's Natural Science Establishment. Thus for forty-eight years he has dealt with minerals, and many of the American specimens obtained by collectors during those years have come to them through his agency.

In this book the author gives the amateur collector the benefit of his long experience. It is not and is not intended to be deeply scientific. In the first part a general but superficial account is given of the physical and chemical properties of minerals, which will serve to induce the reader to take still greater interest in the specimens already in his collection and those he hopes to acquire. Part 2 is devoted to the descriptions of minerals. As the Dana system of classification which is normally used in mineralogical text-books demands considerably more scientific knowledge than the author expects of the ordinary reader, he has adopted a classification in which the species are arranged according to the most important elements in their composition, a cross-reference being given where necessary, while the important group of rock-forming minerals are brought together in the second section. In Part 3 the rocks are briefly considered in three sections: igneous, sedimentary, and metamorphic. Part 4 is an important and original feature of the book. In it an attempt is made to identify any mineral specimen by means of three simple and obvious characters: lustre, hardness, and colour. It is a method which may be expected in skilled hands to yield good results. A novel feature of the book is the pronouncing vocabulary at the end.

The author has added to the usefulness of the book by introducing in the text a large number of drawings and illustrations from photographs, and the ample index is a great advantage.

\section{Interpretative Petrology of the Igneous Rocks}

By Prof. H. L. Alling. Pp. xv+353. (New York and London: MeGraw-Hill Book Co., Inc., 1936.) $24 s$.

THE igneous rocks arise by processes taking place in the physical chemical system of the magma, and the study of the genesis of these rocks is largely concerned with the application of physical chemistry to these systems. Few geologists, however, have this fundamental knowledge-their training has been too broad. It is the aim of this book to present to the geologist those principles of physical chemistry that will enable him to interpret the life-history of these rocks. The phase rule and its application to igneous systems are the basis of the treatment.

The principles of equilibria, solid solution, isomorphism and polymorphism are first examined, and then the various groups of the igneous rock-forming minerals are considered as solid solutions of endmembers, or minals, and their thermal diagrams and optical properties dealt with. Then follows a series of what may be called essays on numerous topies of petrogenesis, such as the crystallization of magmas, diversification of igneous rocks, magmatic assimilation, end-stage processes, and many more.

Whether or not the author has succeeded in his intention of making physical chemistry plain and easy for the geologist - and opinion will certainly be divided on this point - he has at least written a book of great interest to petrologists already learned in this subject. He has, too, provided refreshing and stimulating essays on all those theories that make modern petrology so entertaining. The small scale of some of the illustrations, and a few rather awkward misprints mar an otherwise well-printed book.

\section{Mathematics}

\section{An Illustrated Historical Time Chart of Elementary} Mathematics :

for Senior and Secondary Schools, Training Colleges and Universities. By E. J. Edwards. In 5 sections, each $31 \mathrm{in} . \times 22 \mathrm{in}$. (London : University of London Press, Ltd., 1936.) Thick cardboard, varnished, 21s. net.

MANY teachers of mathematics recognize the advantage of associating the subject with its history, but find difficulty in doing so in the time available. If they decorate the walls of their classrooms with Mr. Edwards's attractive charts, they will have available a stock of interesting information, illustrated with diagrams, maps and portraits, to which incidental reference can be made when appropriate.

The first chart (Beginnings of Mathematics) deals with primitives, Babylon, Egypt and China up to 2000 B.c. The second (Early Mathematics of Egypt, Babylon and China, 2000-1000 B.c.) sketches the development of integers and fractions, and of intuitive and practical geometry. The third (Ancient Greece, $1000-30$ B.c.), perhaps the best of the five, deals with the work of seventeen famous mathematicians. The fourth (Dark Ages, Arab School) brings the account up to 1000 A.D. The fifth (Decline of Arabian and Beginning of European Mathematics. Modern Mathematics, 1000-2000 A.D.) attempts too much. $\mathrm{Up}$ to the time of the invention of the calculus the chart is good, if overcrowded (a fault emphasized by the lettering, which is more artistic than legible), but it would have been better to have omitted all reference to the eighteenth and nineteenth centuries 